\title{
Design, Analysis and Experimental Validation for Fatigue Behavior of a Helical Compression Spring Used For a Two Wheeler Horn
}

\author{
Mr. J. J. Pharne ${ }^{1}$, Dr. R.G.Todkar ${ }^{2}$, Dr.N.D.Sangle ${ }^{3}$ \\ ${ }^{1}$ Lecturer, Dept. of Mechanical Engg., Nanasaheb Mahadik Polytechnic Institute, Peth, Sangli-India) \\ ${ }^{2}$ (Prof. Dept. of Mechanical Engg. ,Annasaheb Dange College of Engineering and Technology, Ashta, Sangli \\ India) \\ ${ }^{3}$ Prof. Dept. of Mathematics, Annasaheb Dange College of Engineering and Technology, Ashta, Sangli- India)
}

\begin{abstract}
Almost all two-wheelers are provided with a facility of a horn to be used to make aware of the presence of the vehicle on road and to maintain a safe distance between two vehicles or to communicate for any other safety reasons. The horn is a crucial element as it is directly related to safety of the vehicle and the person using it. Thus the horn is most important element in the vehicle system and hence it is expected to function properly for a longer time. Most problems of failure of two wheeler horns are due to fatigue failure of spring element in warranty period. A finite element model for helical compression springs subjected to cyclic loads (compression) is developed for fatigue stress analysis. In the design modification of this kind of spring both the elastic characteristics and the fatigue strength have to be considered as significant aspects. A typical helical compression spring used for two wheeler horn is chosen for study under fatigue loading condition. Fatigue analysis is done in ANSYS 14.0 software. The results developed have been compared with the experimental observations. A new design modification is done by introducing another spring coaxially.
\end{abstract}

Keywords: ANSYS 14.0, Finite Element Analysis, Helical compression spring, Fatigue life, Stress analysis.

\section{Introduction}

Springs are mainly used in many devices as members absorbing shock energy as well as for restoring the initial position of a machine component upon displacement for obtaining a given function. Compression springs or coil springs are those which resist compressive forces applied axially. Helical compression springs are crucial components of in many devices including two-wheeler horn system where they are expected to work for a longer life i.e. for more than $10^{6}$ numbers of cycles. Almost all two-wheelers are provided with a facility of a horn to be used to make aware of the presence of two wheeler on road and to maintain a safe distance between two vehicles or to communicate for any other safety reasons. The horn is a crucial element as it is directly related to safety of the vehicle and the person using it. Hence, fatigue failure analysis and life prediction of the helical compression springs used for horns in two wheeler application plays important in order to verify the safe working of horn system during its operational life. Many theoretical and experimental investigations for fatigue failure of helical compression springs have been reported in recent literature. However there is a room for fatigue failure analysis and life prediction of the helical compression springs used for horns in two wheeler applications.

R.K. Luo et. al. [1] has presented a study on fatigue failure of anti-vibration springs, involving both metal and rubber materials based on the actual fatigue loads using continuum mechanics method for the analysis. The investigation, based on the actual fatigue loads, is carried out on these failed and modified products using a method of continuum mechanics including simulation. It is shown that this approach can be employed at a design stage for both metal and rubber fatigue evaluations on anti-vibration springs.

Sid Ali Kaoua et. al. [2] have reported a 3D geometric modeling of a twin helical spring and its finite element analysis to study the spring mechanical behavior under tensile axial loading .A finite element analysis of the mechanical behavior of the twin helical spring under uni-axial tensile load is presented for comparison against those obtained from a theoretical approach based on a transformation of curvilinear coordinates. The is values of von-Mises equivalent stresses have also been determine and compared with those obtained from a theoretical approach based on a transformation of curvilinear coordinates It has been shown that numerical normal stress evolution along the reference fibers (internal radial fibers and external ones) follows a sinusoidal form, and matching those gathered through the theoretical alternative. The advantage of numerical approach related to the ability to access nodal data (internally) so that stress fields (normal, principal and Von-Mises) can be visualized.

C. Madan Mohan Reddy et al [3] have discussed modeling, analysis and testing of suspension spring to replace the existed steel helical spring used in popular two wheeler vehicle for reduction in stress and 
deflections of the helical using the new material. The comparative study is carried out between existed spring and new material spring. Static analysis determines the stress and deflections of the helical compression spring in finite element analysis. The testing proto type is used to test the spring under different loading conditions. Results obtained using experimental investigation is compared with those obtained using FEA and analytical procedure. It has been shown that i) the maximum shear stress of chrome vanadium steel spring has $13-17 \%$ less with compare to hard drawn steel spring. ii) The deflection pattern of the chrome vanadium steel spring $10 \%$ less at specified weight with compare to the hard drawn steel spring. iii) It is observed that $95 \%$ of the similarity in deflection pattern and $97 \%$ similarity in shear stress pattern between experimental values to the analytical values. iv) it is observed that $60 \%$ similarity in between theoretical values of deflection to the experimental values and $85 \%$ similarity in maximum shear stress of spring.

V. K. Aher and P. M. Sonawane [4] presented fatigue analysis of a modified steel leaf spring of a light commercial vehicle (LCV). The non-linear static analysis of 2D model of the leaf spring is performed using NASTRAN solver and compared with analytical results. The fatigue life of the leaf spring is also predicted using MSC Fatigue software. It is shown that the study will help to understand more the behavior of the spring and give information for the manufacturer to improve the fatigue life of the spring using CAE tools. It can help to reduce cost and times in research and development of new product.

Tausif M. Mulla et al [5] presented stress analysis of a helical coil compression spring, which is employed in three wheeler's auto-rickshaw belonging to the medium segment of the Indian automotive market. The static stress analysis using finite element method has been presented.. The elastic behavior and the stress analysis of springs employed in the TWV's front automotive suspension have been presented and discussed in this paper. The results obtained by a fully 3D FE analysis also highlighted the poor accuracy that can be provided by the classical spring model when dealing with these spring geometries. Relative errors on maximum shear stress ranging from 1.5 to 4 per cent, with reference to the applied loads, obtained when compared with the values calculated by using simple analytical model which is found in textbooks. It shows that the shear stress is having maximum value at the inner side of the every coil. The distribution of the stress is similar in every coil. This shows that probability of failure of spring in every coil is same except end turns. In such case residual stress in every coil may be important factor which influence the failure.

W.G. Jiang and J.L. Henshall [6] presented a general and accurate finite element model for helical springs subject to axial loads (extension or/and torsion). Due to the establishment of precise boundary conditions, only a slice of the wire cross-section needs to be modeled; hence, more accurate results can be achieved. Due to the establishment of precise boundary conditions, only a slice of the wire cross-section needs to be modeled; hence, more accurate results can be achieved In general, in has been shown that the FEM results agree well with the analytical models for the tension and torsion springs as the helical angle and the ratio of wire radius to coil radius tend to zero. On the contrary, as a and R/R. increase, the discrepancy between the FEM results and analytical theory increase, probably due to neglecting the high-order terms in the series expansions. The advantages of the present model incorporating helical boundary conditions are not only its accuracy and conciseness, but also that it can be directly extended to model helical springs with arbitrary cross-sections, and material nonlinearity and large deformation ejects can also be conveniently incorporated into the analysis by a multi-step loading process.

The springs used in the bogie suspension of railway coaches are compression springs. They are made of an elastic wire material formed into the shape of a helix. M. Sudhakar Reddy and B. Madhusudhan Reddy [7] presented a study on springs used in the bogie suspension of railway coaches. It is observed that springs used in railway coaches fail prematurely much before their intended service life. Before being put to service, the springs are tested with extensive Non Destructive Testing Methods which are approved by ISO standards to make sure that quality parts are used. However the springs still fail before their service life ends. To study the dynamic behavior of the springs, 3D solid model of helical springs are modeled with PRO/E. Static and Dynamic stress analysis are carried out using ANSYS to understand the Structural and Dynamic response of the springs. Spring behavior has been observed under prescribed or expected loads. Based on the results design modifications has been suggested for better life without failure in service.

Y. Prawoto a et al [8] presented a study on automotive suspension coil springs, their fundamental stress distribution, materials characteristic, manufacturing and common failures. An in depth discussion on the parameters influencing the quality of coil springs is also presented. Several case studies of suspension spring failures ranging from the very basic including insufficient load carrying capacity, raw material defects such as excessive inclusion levels, and manufacturing defects such as delayed quench cracking, to failures due to complex stress usage and chemically induced failure have been discussed including FEA stress distributions around typical failure initiation sites. 


\section{Design Of A Helical Compression Spring Under Axial Load}

The design of a compression spring under axial load involves the following considerations:

Space into which the spring must fit and operate, Values of working forces and corresponding deflections, Operational accuracy and reliability needed, Tolerances and permissible variations in specifications, Environmental conditions such as temperature, presence of a corrosive atmosphere, Cost and qualities needed. The primary design constraints are that i) the wire size should be commercially available and that the stress at the solid length be no longer greater than the torsional yield strength. ii) Functioning is expected to be stable.

The maximum shear stress at the inside of the coil given by,

$\tau_{\max }=\frac{8 P D}{\pi d^{3}} \mathrm{~K} \quad$ Where, $\mathrm{K}=\left[\frac{4 \mathrm{c}-1}{4 \mathrm{c}-4}+\frac{0.615}{\mathrm{c}}\right]$ and is called as Wahl's factor and used for considering stress correction because of curvature effect and $\mathbf{C}=\mathbf{D} / \mathbf{d}$ is called as spring index. Stress obtained by the imperial result can be cross checked by finite element method for better understanding of the stress distribution. The deflection of spring end $\delta$ can be calculated as $\delta=\left(8 \mathrm{PD}^{3} \mathrm{~N} / \mathrm{Gd}^{4}\right)$ where, $\mathrm{P}$ is the axially applied load.

\section{Finite Element Analysis}

A primary reason to use FEA in coil design is to reduce the error caused by simplifications of the equations. The most accurate FEA results can be obtained by creating 3-D parts of a coil spring, followed by using finer meshing of the parts with 3-D solid element. For the FEA work a helical spring currently used in modern two wheeler horn has been selected having the specifications shown in Table 1

Table 1. Spring specifications (stainless steel spring)

\begin{tabular}{|l|l|}
\hline Outer diameter Do mm & 4.8 \\
\hline Inner diameter Di mm & 3.9 \\
\hline Mean diameter D mm & 4.35 \\
\hline Wire diameter d mm & 0.450 \\
\hline Spring index C & 9.67 \\
\hline
\end{tabular}

\begin{tabular}{|l|l|}
\hline Free length Lf mm & 10.2 \\
\hline Solid length Ls mm & 2.7 \\
\hline Number of active turns N & 4 \\
\hline Number of Total Turns & 6 \\
\hline Pitch & 2.04 \\
\hline
\end{tabular}

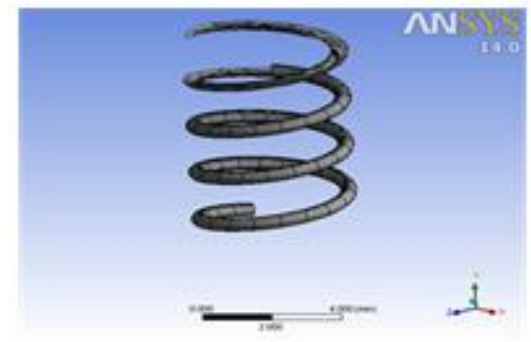

Fig. 1: Meshing of single spring.

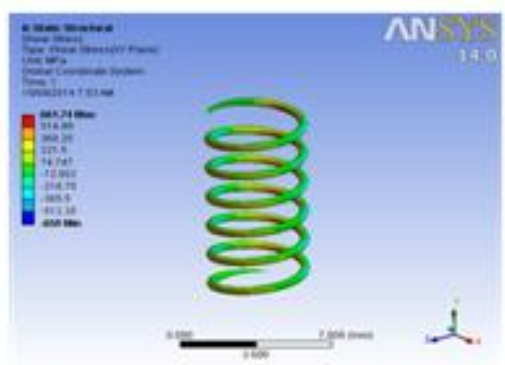

Fig. 3: Shear stress in single spring

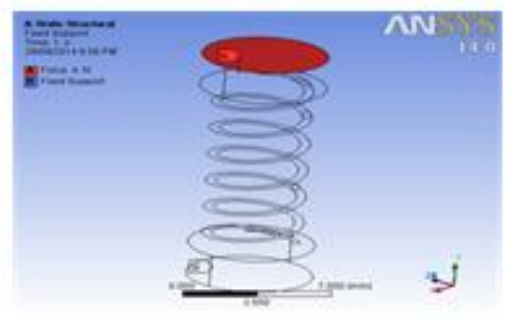

Fig. 2: force applied at one end

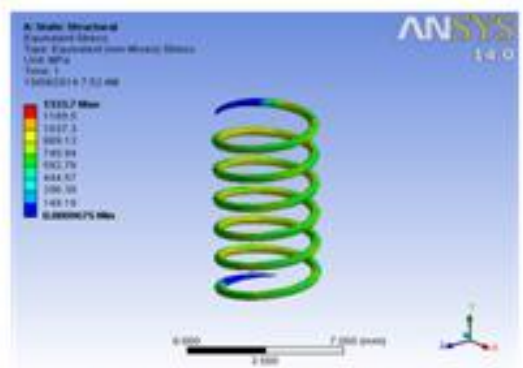

Fig. 4: von-Mises stresses in single spring 


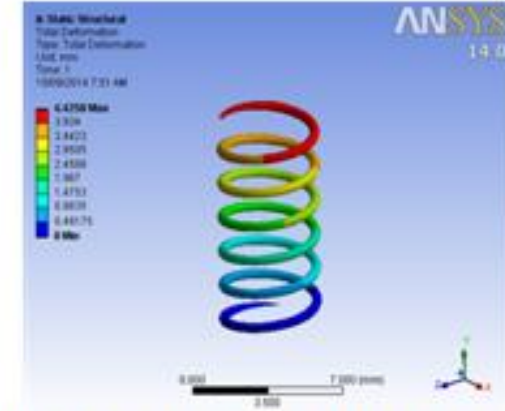

Fig. 5: Total deformation in the single spring

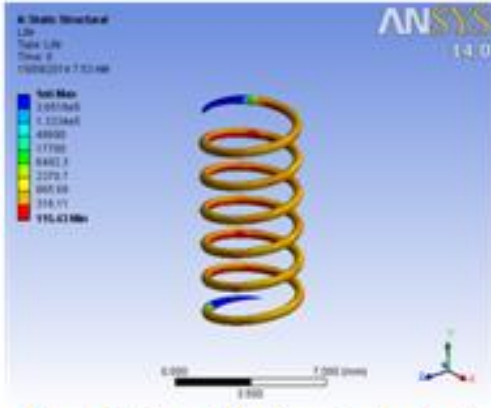

Fig. 6: Failure life of spring (cycles)

For this work the softwares used are PRO-E for solid modeling ( Fig. 1, Fig. 2 ) and ANSYS 14 for analysis of shear stresses developed (Fig. 3,) , von-Mises stresses in single spring (Fig. 4) and total deformation (Fig. 5) when single spring is used and life of spring in number of cycles needed for failure (Fig. 6 ). It is seen that the life of single spring is observed to be in between 115 cycles to 6492 cycles. The criterion for acceptance of the spring was it should sustain minimum 3 lakh cycles.

\section{Design Modification}

The experimental investigations and customers report show that the spring under investigation has high response to fatigue and failure chances are more. The modification in fatigue life can be based on i) change of material and ii) change of the geometrical shape. The first case is not recommended because of availability of space for the spring in the final assembly. Hence a design modification with co-axial spring has been done in the design of single compression spring. Keeping the coil outer diameter and free length of the spring same, an inner spring mean with coil diameter is $2.17 \mathrm{~mm}$ has been added without changing the wire diameter and number of active coils.

Table 2: Modified Spring specifications (stainless steel spring)

\begin{tabular}{|l|l|l|}
\hline Parameter & $\begin{array}{l}\text { Outer } \\
\text { Spring }\end{array}$ & $\begin{array}{l}\text { Inner } \\
\text { Spring }\end{array}$ \\
\hline Outer diameter Do mm & 4.8 & 2.62 \\
\hline Inner diameter Di mm & 3.9 & 1.72 \\
\hline Mean diameter D mm & 4.35 & 2.17 \\
\hline Wire diameter d mm & 0.45 & 0.45 \\
\hline Spring Index C & 9.67 & 9.67 \\
\hline
\end{tabular}

\begin{tabular}{|l|l|l|}
\hline Parameter & $\begin{array}{l}\text { Outer } \\
\text { Spring }\end{array}$ & $\begin{array}{l}\text { Inner } \\
\text { Spring }\end{array}$ \\
\hline Solid length Ls mm & 2.7 & 2.7 \\
\hline Number of active turns N & 4 & 4 \\
\hline Number of total turns & 6 & 6 \\
\hline Pitch p mm & 2.04 & 2.04 \\
\hline Spring rate N/mm & 1.26 & 0.39 \\
\hline
\end{tabular}

\subsection{Finite Element Modeling of Modified Compression Spring}

For this work the softwares used are PRO-E for solid modeling (Fig. 7, Fig. 8) and ANSYS 14 for analysis of shear stresses developed (Fig 9), von-Mises stresses in single spring (Fig 10) and total deformation when single spring is used (Fig. 11) and life of spring in number of cycles needed for failure (Fig. 12). Cut section of the modified new design is shown in Fig. 13. It is seen that the life of modified spring is observed to be upto $10^{6}$ cycles which is more than expected.

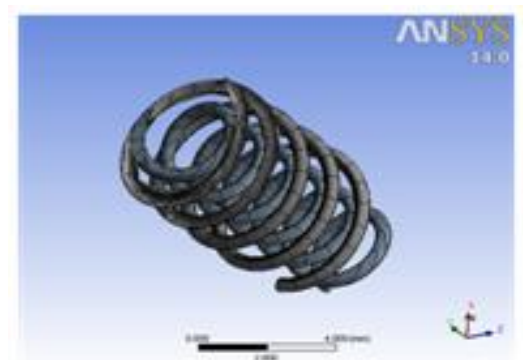

Fig. 7: Meshing of single spring.

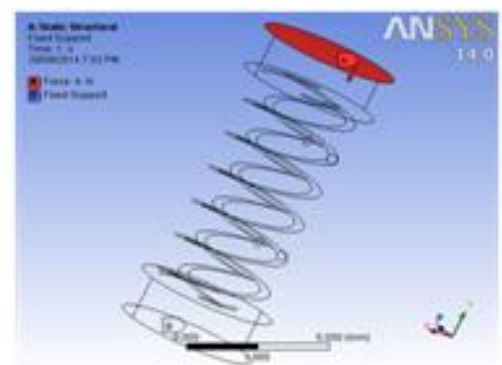

Fig. 8: Force applied at one end 


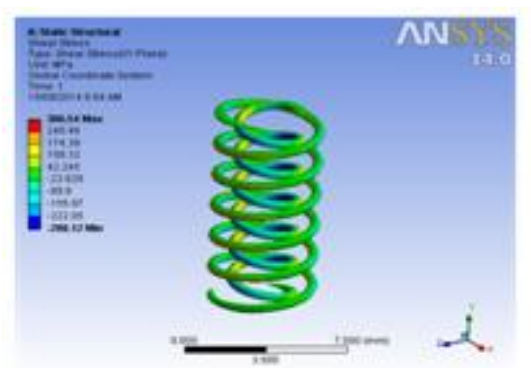

Fig.9: Shear stress in new design spring

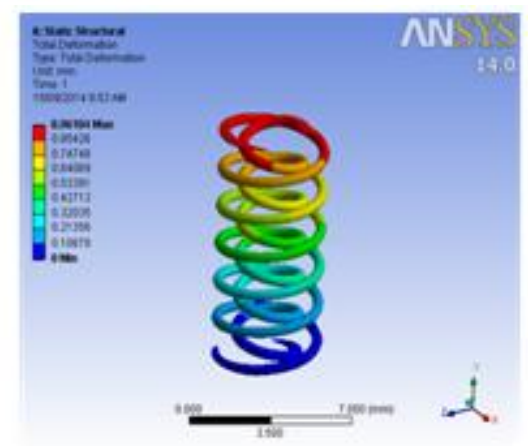

Fig. 11: Total deformation in new design spring

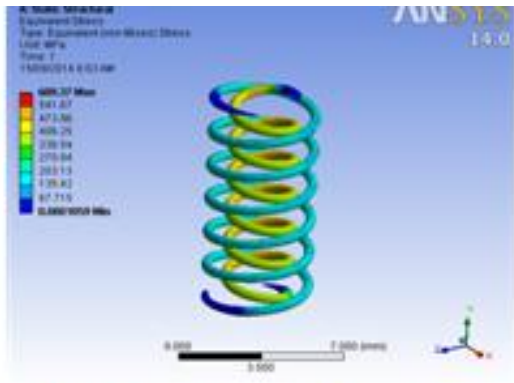

Fig.10: von-Mises stresses new design

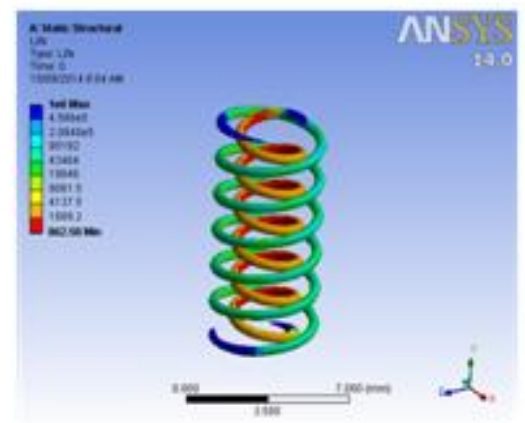

Fig. 12: Failure life of spring (cycles)

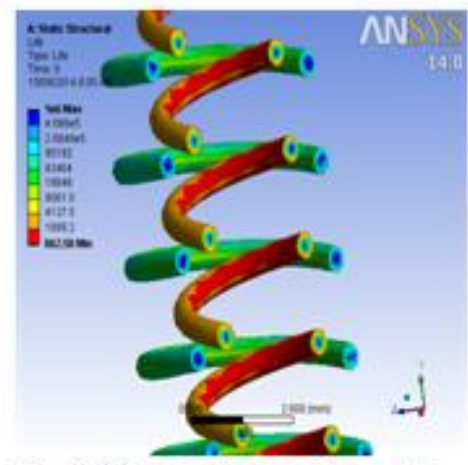

Fig. 12: Sectional view of new design

\section{Experimental Investigation}

The experimental study was carried out by using "Special Purpose Fatigue Testing Machine" for design validation. The fatigue testing machine has following specifications.

\section{Table 3: Specifications of Fatigue Testing Machine}

\begin{tabular}{|l|l|}
\hline Operation & Fully automatic \\
\hline Maximum load kg & 200 \\
\hline Minimum load kg & 0.3 \\
\hline Stroke length mm & 1.5 to 200 \\
\hline Max speed cycles/hr & 12000 \\
\hline Machine weight kg & 700 \\
\hline
\end{tabular}

Note: The springs having mean coil diameter ranging from $2 \mathrm{~mm}$ to $250 \mathrm{~mm}$ can be tested for fatigue failure using the test rig.

A random sample consisting five springs selected from a lot of 100 springs was taken for experimental investigation under following testing conditions.
a. Working temperature: Room temperature.
b. Stroke: $5 \mathrm{~mm}$ deformation
c. Frequency: 1 cycle/sec
d. Cycle to be completed: 3 lakh cycle 


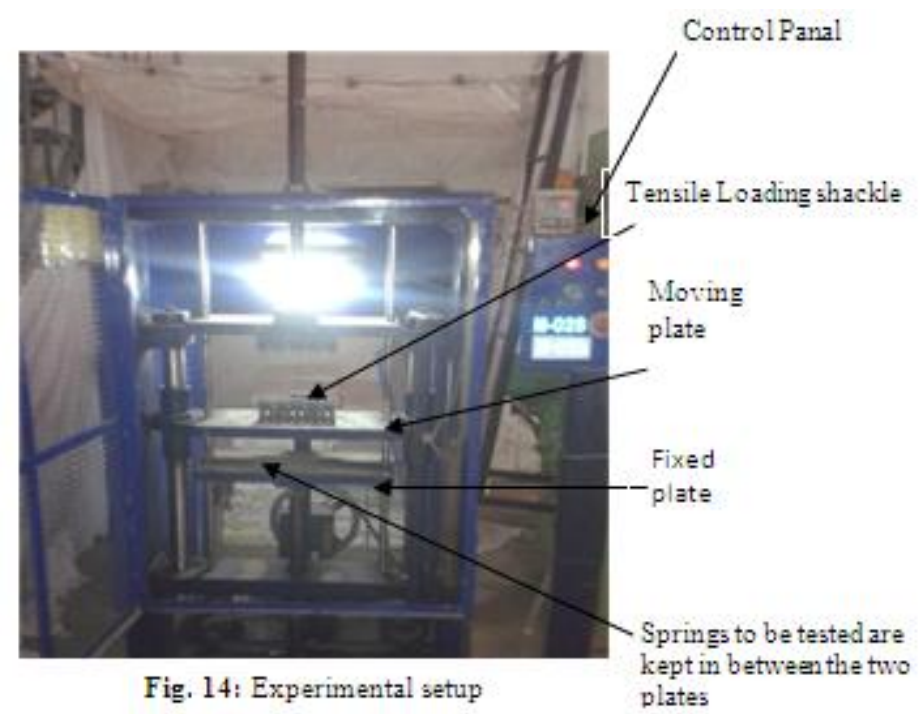

VI. Observations

At the end of 3 lakh cycles, no cracks or breakages were found in any of the five modified springs under experimental investigation. Table 3 shows the results of experimental investigation in detail.

Table 4: Result comparisons between original and modified spring

\begin{tabular}{|l|l|l|l|l|l|}
\hline Sr. & \multirow{2}{*}{\begin{tabular}{l}
\multirow{2}{*}{ No. } \\
Parameters
\end{tabular}} & SINGLE SPRING & \multicolumn{2}{l|}{ MODIFIED SPRING } \\
\cline { 2 - 5 } & & Min & Max & Min & Max \\
\hline 1 & Shear stress MPa & 74 & 661 & 42 & 306 \\
\hline 2 & Deformation after test mm & 0 & 4.42 & 0 & 0.96 \\
\hline 3 & von-Mises stress MPa & 0 & 1333.7 & 0 & 609 \\
\hline 4 & Life (cycles) & 115 & 6492 & 862 & $10^{6}$ \\
\hline
\end{tabular}

VII. Discussions Of Results And Conclusion

Initially a single spring (spring rate of $1.26 \mathrm{~N} / \mathrm{mm}$ ) was modeled for dynamic analysis and prediction regarding shear stress disturbance, von-Mises stresses, deformation and fatigue life using ANSIS 14.0. The results show that there was a permanent deformation of the spring by $4.425 \mathrm{~mm}$ and the maximum fatigue life was 6492 cycles.

As these predictions are not acceptable, the spring assembly was modified by adding one more spring in series maintaining the assembly configurations ( outer spring rate of $1.26 \mathrm{~N} / \mathrm{mm}$ in series with inner spring rate of $0.39 \mathrm{~N} / \mathrm{mm}$ ). The results show that there was a permanent deformation of the modified spring by 0.74 $\mathrm{mm}$ and the maximum fatigue life was upto $10^{6}$ cycles. These theoretical predictions are found to be acceptable.

The modified spring was manufactured and tested as described. The experimental results show that at the end of 3 lakh cycles, no cracks or breakages were found in any of the five modified springs under experimental investigation.

\section{Future Scope}

The low cost consideration can be achieved by changing the spring material as composite material with different compositions.

\section{Acknowledgments}

The authors would like to thank The Management of Annasaheb Dange College of Engineering and Technology, ASHTA, for providing us necessary technological and laboratory facilities as and when needed. The efforts taken by M/s. Able technologies (I) Pvt. Ltd. Pune, to provide the research project, entire experimental setup and technical knowhow during experimental investigation including man power are highly appreciated.

\section{References}

[1]. R.K. Luo a , W.J. Mortel ${ }^{\mathrm{a}}$, X.P. Wu "Fatigue failure investigation on anti-vibration springs" Engineering Failure Analysis 16 (2009) 1366-1378

[2]. Sid Ali Kaoua a, Kamel Taibi a, Nacera Benghanem a, Krimo Azouaoui b, Mohammed Azzaz “ a Numerical modelling of twin helical spring under tensile loading." Applied Mathematical Modelling, 35 (2011) 1378-1387. 
[3]. C. Madan Mohan Reddy ${ }^{1}$, D.Ravindra Naik ${ }^{2}$, Dr M.Lakshmi Kantha Reddy ${ }^{3}$, “Analysis and Testing of Two Wheeler Suspension Helical Compression Spring” IOSR Journal of Engineering (IOSRJEN) ISSN (e): 2250-3021, ISSN (p): 2278-8719 Vol. 04, Issue 06 (June. 2014), ||V1\| PP 55-60.

[4]. Mr. V. K. Aher, Mr. P. M. Sonawane, "Static And Fatigue Analysis Of Multi Leaf Spring Used In The Suspension System Of LCV", International Journal of Engineering Research and Applications (IJERA) ISSN: 2248-9622 , Vol. 2, Issue4, July-August 2012, pp.1786-1791.

[5]. Tausif M. Mulla ${ }^{1}$, Sunil J. Kadam², Vaibhav S. Kengar ${ }^{3}$, "Finite Element Analysis Of Helical Coil Compression Spring For Three Wheeler Automotive Front Suspension" International Journal of Mechanical and Industrial Engineering (IJMIE) ISSN No. 2231 6477, Vol-2, Iss-3, 2012

[6]. W.G. Jiang a , J.L. Henshall ' , "A novel finite element model for helical springs", Finite Elements in Analysis and Design 35 (2000) 363-377

[7]. M.Sudhakar Reddy ${ }^{1}$, B.Madhusudhan Reddy ${ }^{2}$, "The Study of Premature Failure of Springs Used In Railway Coaches" IOSR Journal of Mechanical and Civil Engineering (IOSR-JMCE) e-ISSN: 2278-1684,p-ISSN: 2320-334X, Volume 8, Issue 5 (Sep. Oct. 2013), PP 19-28

[8]. Y. Prawoto a , M. Ikeda a, S.K. Manville a, A. Nishikawa a,b "Design and failure modes of automotive suspension springs" Engineering Failure Analysis 15 (2008) 1155-1174

[9]. V.B. Bhandari, Design of Machine Elements (New Delhi, Tata McGraw-Hills,2009). 